\title{
As culturas populares nas políticas culturais: Uma disputa de sentidos
}

\section{Las culturas populares en las políticas culturales: Una disputa de significados}

\author{
Popular cultures in cultural policies: A dispute of meanings \\ Jocastra Bezerra ${ }^{1}$ \\ Alexandre Barbalho ${ }^{2}$
}

Palavras chave:

O objetivo deste artigo é compreender os usos da noção de "cultura popular" presente nos documentos do Ministério da Cultura (MinC)

Cultura Popular no governo Lula. Tal recorte se impõe quando se constata que, a partir de 2003, a defesa e a promoção das culturas populares se

Política Cultural fazem por meio de novas questões e de uma ampliação conceitual que envolve o patrimônio (material e imaterial), as identidades (no

Discurso plural) e a diversidade cultural brasileira. A pesquisa documental, bem

Identidade como depoimentos de agentes envolvidos no processo compõem o

Diversidade corpus, para cuja análise utilizamos, principalmente, o aporte teórico de Ernesto Laclau e Chantal Mouffe. 
Resumen:

El objetivo de este trabajo es comprender los usos del término "cultura popular" en los documentos del Ministerio de Cultura en el gobierno Lula. Esto marco se justifica cuando se señala que, desde 2003, la defensa y la promoción de las culturas populares se hacen a través de nuevos temas y una expansión conceptual que implica lo patrimonio (tangible e intangible), las identidades (en plural) y la diversidad cultural brasileña. La pesquisa documental, así los testimonios de los agentes que participan en el proceso constituyen el corpus, a cuyo análisis se utilizará principalmente la contribución teórica de Ernesto Laclau y Chantal Mouffe.

Palabras clave:

Cultura Popular

Política Cultural

Discurso

Identidad

Diversidad

\section{Keywords:}

Popular Culture

Cultural Policy

\section{Discourse}

Identity

Diversity

\section{Abstract:}

The objective of this paper is to understand the uses of the term "popular culture" found in the documents of the Ministry of Culture (MinC) in the Lula government. This frame is required when it finds that, from 2003, the defense and promotion of popular cultures are made through new issues and a conceptual expansion involving the heritage (tangible and intangible), the identities (plural) and Brazilian cultural diversity. The desk research as well as testimonies of those involved in the process make the corpus, for which analysis we use mainly the theoretical contribution of Ernesto Laclau and Chantal Mouffe. 


\section{As culturas populares nas políticas culturais: uma disputa de sentidos}

\section{Introdução}

A cultura vem assumindo, no Brasil, uma crescente centralidade nos projetos de desenvolvimento e de construção da cidadania. Nesse contexto, tem se proliferado estudos sobre as políticas culturais brasileiras nas mais diversas disciplinas. Contudo, a atenção dada às políticas voltadas especificamente para o segmento das culturas populares ainda é tímida, embora a valorização do popular seja elemento central em discursos e projetos governamentais.

Entendendo que a política cultural define conceitos e significados em um campo de enfrentamentos (BARBALHO, 2005), a atuação do Estado na promoção das culturas populares insere-se nos debates acerca da própria formulação da noção "cultura popular" - noção esta que vem sendo construída, diacrônica e sincronicamente, por diferentes grupos políticos, sociais e culturais, o que resulta em uma polissemia de sentidos, muitas vezes dissonantes, e em relações de conflitos e disputas.

O objetivo deste artigo é compreender os usos da noção de "cultura popular" presente no Ministério da Cultura (MinC) no governo Lula. Tal recorte se impõe quando se constata, como veremos, que, a partir de 2003, a defesa e a promoção das culturas populares se fazem por meio de novas questões e de uma ampliação conceitual que envolve o patrimônio (material e imaterial), as identidades (no plural) e a diversidade cultural brasileira.

A pesquisa documental, bem como depoimentos de agentes envolvidos no processo compõem o corpus, para cuja análise utilizamos, principalmente, o aporte teórico de Ernesto Laclau e Chantal Mouffe. Tal escolha justifica-se pelo fato desses autores, bem como outros pensadores, entenderem o discurso como prática social, constituído de poder e ideologias. O discurso é, assim, capaz de construir dimensões sociais de conhecimento, relações e identidades sociais (LACLAU; MOUFFE, 1987 ; MAGALHÃES, 2001).

O discurso se constitui, para Laclau e Mouffe, como uma prática articulatória, ou seja, "toda prática que estabelece una relación tal entre elementos, que la identidad de éstos resulta modificada como resultado de esa prática". Por sua vez, o discurso é a "totalidad estructurada resultante de la práctica articulatória" (LACLAU; MOUFFE, 1987, p. 176). Nessa perspectiva, conforme analisam Oliveira e Lopes, a formação discursiva é um conjunto articulado heterogêneo de discursos, ou seja, "um sistema de regras de produção de sentido, já hegemonizada por um determinado discurso dentro de uma pluralidade" (OLIVEIRA; LOPES, 2011, p. 15). O discurso não se constitui como um todo homogêneo, fechado em si, mas consegue aglutinar e articular, de forma contingente e provisória, diferentes sentidos em disputa a partir de efeitos de posicionamento dos sujeitos.

Por esse viés analítico, pode-se entender como os discursos da política cultural, e mais especificamente a construção conceitual acerca da cultura popular, representam uma articulação hegemônica de forma contingente e provisória. De acordo com essa ideia, o objeto do discurso, em nosso caso a noção de "cultura popular", está marcado pelo contexto de sua constituição. Quando determinados sentidos já não dão conta dos fatores característicos de um período histórico torna-se necessário um 
novo discurso, uma nova hegemonia de sentidos, para representar o momento que se inaugura (MENDONÇA, 2012). O deslocamento é, assim, uma mudança na centralidade de significações, o que expõe as disputas e conflitos que permeiam a prática articulatória na qual as diferenças e significações em disputa conseguiram ser articuladas e determinados sentidos foram hegemonizados.

\section{A cultura popular nas políticas cul- turais no Brasil}

Não é o caso de fazermos aqui uma ampla retrospectiva do processo de constituição das políticas culturais e, mais especificamente, daquelas voltadas para a cultura popular. O que nos interessa é pontuar transformações operadas ao longo do tempo e que permitam compreender o que há de novo na política cultural a partir do governo Lula, nosso foco central.

Assim, até meados de 1930, o Brasil não possuía um campo de políticas culturais minimamente estruturado, embora os primeiros passos nesse sentido tenham acontecido com a vinda da Corte Real em 1808 (BARBALHO, 2009). É somente com o governo Vargas (1930-45), que a ação político-cultural do Estado toma características de atuação, abrangência e estruturação a ponto de se configurar como política pública. A questão de ordem é a da construção e da valorização da nacionalidade, a partir de uma pretensa identidade expressa em um "Ser Nacional". O popular, ou o folclore, retirado do local onde é elaborado, ocultando assim as relações sociais das quais é produto, funciona, nesse momento de constituição da "cultura brasileira", como força de união entre as diversidades regionais e de classe. O Estado, portanto, direciona a ação do governo para a valorização da cultura popular transformada em símbolo da cultura nacional (BARBALHO, 1998)
O período democrático que se segue após a Era Vargas, de 1945 a 1964, é marcado pela frágil presença do Estado na direção e formulação da política cultural, com exceção de algumas ações, entre as quais se destacam, para o nosso interesse, as criações do Instituto Superior de Estudos Brasileiros (ISEB), com seu ideário desenvolvimentista, da Comissão Nacional de Folclore (CNFL), em 1947, no âmbito do Instituto Brasileiro de Educação, Ciência e Cultura (IBECC) e da Campanha de Defesa do Folclore (1953).

A articulação entre a Comissão Nacional de Folclore, a Campanha de Defesa do Folclore e o Movimento Folclórico representou o período de maior vitalidade do folclore no Brasil, com a formalização dos estudos acadêmicos e a criação de museus em diversos estados no país (CORREA, 2012). Paradoxalmente, é a partir dos anos 1950, com o projeto e a ideologia desenvolvimentistas, que a noção de folclore passa a ser sinônimo de atraso cultural e adquire um significado negativo. Deste modo, começa a ser formulada uma distinção entre folclore e cultura popular, que conduz a um deslocamento significativo dessas categorias (ORTIZ, 2006 ; ALVES, 2011).

Com a instauração do governo militar, em 1964, ocorreu uma retomada do dirigismo do Estado no campo das políticas culturais que visava à integração simbólica do país através da reprodução e legitimação da ideologia oficial com a circulação de bens simbólicos (filmes, músicas, e livros) nos meios de comunicação, que estavam sob seu rígido controle. Essa política de integração simbólica atrelava-se à ideia de identidade nacional, que reivindicava o "resgate" de uma "cultura brasileira autêntica". Nesse contexto destaca-se, para os nossos interesses, a criação em 1975 da Fundação Nacional das Artes que deu importante apoio à preservação dos valores culturais das manifestações artís- 
ticas e tradicionais. Em 1979, a instituição se vinculou à Campanha de Defesa do Folclore Nacional, restaurada como Instituto Nacional do Folclore.

Também em 1975, na direção do Centro Nacional de Referência Cultural (CNRC), Aloísio Magalhães defende um conceito mais abrangente de cultura, com atenção prioritária às manifestações culturais tradicionais e populares (BOTELHO, 2007). Quando assume em 1979 a direção da Fundação Nacional Pró-Memória, Magalhães aciona a noção de bens culturais com a qual pretendia identificar manifestações e saberes populares, como o artesanato, as tecnologias tradicionais, as artes e ofícios populares. O seu trabalho amplia e atualiza a questão patrimonial, considerando não só os bens materiais (móveis e imóveis), mas privilegiando a produção coletiva, os saberes, fazeres, comportamentos e expressões populares como patrimônio cultural brasileiro (RUBIM, 2007 ; CORREA, 2012).

Com o fim da ditadura militar, inicia-se o processo de redemocratização do país em meio a um ciclo de sucessivas crises financeiras, que revela um cenário de profundas desigualdades econômicas e sociais (1985-1993). No campo das políticas públicas de cultura há um esvaziamento de recursos públicos e o desmonte de instituições culturais. Por outro lado, passa a existir uma contínua transferência para o setor privado da responsabilidade de incentivo à produção cultural. Nesse cenário, é criada a primeira lei de incentivo à cultura no Brasil, em 1989, a Lei Sarney, que será sucedida pelas Leis Rouanet e do Audiovisual. Tais leis privilegiam o financiamento dos projetos da sociedade civil, mas o investimento não é mais feito diretamente pelo Estado - ainda que os recursos utilizados continuem públicos mas pelo mercado, por meio do mecanismo da renúncia fiscal.
Nesse contexto, há um declínio do interesse do Estado pela cultura popular, o que se comprova pelas parcas referências a esse segmento nas políticas culturais dos governos Sarney, Collor, Itamar e Fernando Henrique Cardoso. Um dos poucos registros encontrados se refere ao Programa Artesanato Solidário, que fazia parte da Comunidade Solidária, projeto de combate à exclusão social e à pobreza, criado em 1995, pela primeira dama Ruth Cardoso. Paradoxalmente, nesse período realiza-se o "Seminário do Patrimônio Imaterial: Estratégias e Formas de Proteção", organizado pela superintendência do Instituto do Patrimônio Histórico e Artístico Nacional (Iphan) do Ceará, em 1997, que teve como principal resultado a constituição do Grupo de Trabalho Patrimônio Imaterial, responsável pela formulação do Programa Nacional do Patrimônio Imaterial em 2000.

\section{Governo Lula: novas questões, inte- resses e atores}

A partir de 2003, com o início do governo Lula, tem-se uma nova retomada do interesse pelas culturas populares no campo das políticas públicas de cultura, que corresponde ao discurso mais amplo do governo de inclusão de novos sujeitos sociais (classe trabalhadora, segmentos marginalizados, minorias sociais etc.). Entendemos que a defesa e a promoção das culturas populares no cenário atual apresentam outra construção discursiva, que aciona novas categorias, questões, interesses e atores, e possibilita a legitimação das políticas públicas para essas culturas.

Tal retomada se relaciona fortemente ao cenário internacional, no qual, sobretudo, no pós-guerra, ganha força um movimento global que reivindica a regulamentação e normatização para o campo da cultura. Em face das profundas transformações ocorridas nessa segunda metade do sécu- 
lo - como a expansão e dinamização dos mercados culturais, o avanço das novas tecnologias da informação, os movimentos e conflitos de matriz étnico-religiosa - diversos estados nacionais e organismos transnacionais começam a defender a elaboração de políticas culturais para a proteção de culturas "ameaçadas" pelos processos da globalização - mercantilização e homogeneização cultural - e acionam a cultura como estratégia para o desenvolvimento social e econômico das nações, e diálogo e tolerância entre os povos (ALVES, 2011).

A Organização das Nações Unidas para Educação Ciência e Cultura (UNESCO) é o organismo internacional catalisador das discussões e o responsável pela implementação de uma série de medidas para formulação de políticas culturais pelos países membros. O trabalho da UNESCO é de natureza normativa, mas desempenhou, sobretudo, um papel conceitual no que se refere à construção discursiva das categorias ligadas à cultura, que ganham força nesse início de século XXI: identidade, diversidade cultural, culturas populares e patrimônio imaterial.

Como resultado dos debates realizados em uma série de encontros e convenções, a UNESCO publica a Carta de Recomendação sobre a Salvaguarda da Cultura Tradicional e Popular, em 1989, que estimula a criação de políticas regulamentadoras. A Carta é o primeiro documento internacional que apresenta uma definição de cultura tradicional e popular (UNESCO, 1989). Mas são dois instrumentos mais recentes da UNESCO, a Convenção para a Salvaguarda do Patrimônio Cultural Imaterial (2003) - que reconhece as práticas, representações, expressões e manifestações culturais como patrimônio imaterial - e a Convenção Sobre a Proteção e a Promoção da Diversidade das Expressões Culturais (2005), que constituem os referenciais básicos das ações realizadas no Brasil (MinC, 2010).
É nesse cenário que o Estado brasileiro fala sobre a identidade nacional, agora pluralizada a partir de sua riqueza de identidades locais e da diversidade cultural. Em seu discurso de posse, Gilberto Gil (2004) afirma que se inaugura uma "nova fase na política cultural do país" que reserva ao Estado a responsabilidade por todas as esferas da produção cultural da sociedade brasileira - na sua diversidade de manifestações em suas matizes étnicas, religiosas, de gênero, regionais, além de impulsionar a dimensão cultural do desenvolvimento. A sua gestão, defende o ministro, se focará em revelar os "brasis", através da implementação de programas e ações direcionados a todos os "cantos e recantos do Brasil".

Gil também afirmou que romperia com as hierarquias das concepções de cultura popular e erudita, assim como com a assimilação do conceito de cultura popular à noção de folclore: "Ninguém vai me ouvir pronunciar a palavra 'folclore' [...]. Os vínculos entre o conceito erudito de 'folclore' e a discriminação cultural são mais do que estreitos. [...] Não existe 'folclore' - o que existe é cultura" (GIL, 2003, p. 41). Interessante destacar que o MinC passa a adotar em seu discurso (documentos e falas oficiais) o uso plural da palavra cultura popular, assim como também passa a ser recorrente "o uso no plural de palavras como política, identidade e cultura: as políticas públicas, as identidades nacionais e as culturas brasileiras" (BARBALHO, 2007, p. 13).

As expressões "cultura popular tradicional" ou "culturas populares", e mais recentemente "patrimônio imaterial", passam a ser utilizadas em substituição à "folclore" na maioria dos programas e ações, a fim de se evitar as interpretações e visões conservadoras que o termo historicamente adquiriu. Nesses deslocamentos de sentido, as transformações e atualizações nas noções de cultura popular e patrimônio imaterial mantêm aproxi- 
mações que permitem, muitas vezes, que sejam intercambiáveis nos discursos das políticas públicas em razão das próprias orientações e do campo discursivo norteador da UNESCO.

Retomando a política cultural do Governo Lula, na reestruturação do MinC, o Centro Nacional de Folclore e Cultura Popular (CNFCP), representante tradicional dos campos das culturas populares e do folclore, saiu da competência da Funarte e passou a ser autarquia do Iphan. De acordo com Correa, essa mudança "indicou uma compreensão, por parte do novo quadro de gestão ministerial, das manifestações folclóricas e populares mais voltadas para a ótica patrimonial" (CORREA, 2012, p. 54). Deste modo, o CNFCP e o Departamento de Patrimônio Imaterial (DPI/Iphan) passaram a ser responsáveis pelas ações de preservação da memória e salvaguarda de grupos e expressões da cultura popular.

As culturas populares também foram contempladas em outras secretarias na estrutura organizacional do MinC, como, por exemplo, pela Secretaria da Identidade e da Diversidade Cultural (SID/MinC), responsável pela realização de seminários e editais destinados às expressões populares; e pela Secretaria de Programas e Projetos Culturais (SPPC), que, por meio do Programa Cultura Viva e especialmente da Ação Ponto de Cultura, abriu amplo espaço para as culturas populares (com Pontos de jongo, fandango, maracatu, reisado, hiphop, entre outros); e por meio da criação da Ação Griô, que promove o diálogo de mestres populares com espaços formais e não formais de educação.

Nesse contexto, em 2007, foram instituídas a Política Nacional de Desenvolvimento Sustentável dos Povos e Comunidades Tradicionais (PNPCT), com o objetivo de promover o desenvolvimento sustentável dos povos e comunidades tradicionais, e o Programa de Promoção das Culturas Populares (PPCP), com o objetivo de fortalecer, proteger e difundir a diversidade cultural das culturas populares do Brasil.

Exploramos a seguir as mais significativas ações e programas do MinC, nos governos Lula, no campo das políticas públicas para a proteção e promoção das culturas populares: (1) a Secretaria da Identidade e da Diversidade Cultural (SID/ MinC); (2) o Programa Nacional do Patrimônio Imaterial (PNPI); (3) o Programa Nacional de Cultura, Educação e Cidadania - Cultura Viva, e sua ação prioritária, o Ponto de Cultura.

\section{Políticas para a diversidade cultural brasileira - (SID/MinC)}

Em 2003, o MinC criou a Secretaria da Identidade e da Diversidade Cultural (SID) - atualmente integrada à Secretaria de Cidadania e Diversidade Cultural (SCD). A SID se comprometeu em promover o diálogo e atender às demandas dos movimentos, grupos e setores representativos da diversidade cultural brasileira desprovidos do acesso às políticas públicas. Com esse objetivo realizou seminários e congressos com grupos de trabalho formados por segmentos culturais específicos considerados prioritários, e assim passou a definir suas ações. A SID realizou dois importantes Seminários de Políticas Públicas para as Culturas Populares, que reuniu as demandas, estabeleceu metas e prioridades para essas culturas.

Em 2005, foi realizado o I Seminário de Políticas Públicas para as Culturas Populares, em parceria com a Fundação Cultural Palmares, o CNFCP do Iphan e a Secretaria de Políticas Culturais (SPC/ MinC). A segunda edição do Seminário aconteceu em 2006, em consonância 
com o I Encontro Sul-Americano das Culturas Populares. A realização dos Seminários inicia o processo de participação dos segmentos da cultura popular na elaboração de políticas públicas. A fala de Sérgio Mamberti, então secretário da SID, traz elementos que ressaltam a política de inclusão social mediante os processos participativos:

Ao longo da história, a exclusão dos segmentos populares das políticas públicas do nosso país, bem como a segregação social e racial, tem sido fatores determinantes na desvalorização de sua produção cultural [...]. Este é um ponto fundamental: os processos participativos atuam como indutores do fortalecimento da sociedade civil, dos grupos e redes culturais das culturas populares (MAMBERTI, 2005, p. 21/23).

Como resultado dos Seminários, foi elaborado o Plano Setorial para as Culturas Populares (PSCP), aprovado em 2010, como documento estruturante das ações e políticas a serem implementadas para as culturas populares e parte integrante do Plano Nacional de Cultual (PNC). As diretrizes do plano visam contribuir para a valorização e o fortalecimento dessas culturas e de seus praticantes por meio do mapeamento das manifestações e expressões; fortalecimento da transmissão de saberes e fazeres; manutenção e desenvolvimento sustentável para a produção, circulação e fruição das culturas populares; qualificação da gestão cultural; simplificação dos mecanismos de fomento; ampliação da visibilidade das manifestações das culturas populares; e estabelecimento da intersetorialidade das políticas públicas (MinC, 2010).

Outra importante ação da SID é o Programa Identidade e Diversidade Cultural - Brasil Plural, criado em 2004, cujo objetivo é garantir a grupos e redes de agentes culturais constituintes da diversidade de expressões culturais brasileiras o acesso aos recursos para o desenvolvimento de suas ações, priorizando, sobretudo, a inclusão de grupos até então marginalizados ou com acesso limitado às políticas culturais (SANTOS et al., 2010). Dentre as ações do Brasil Plural, estão os editais e prêmios dirigidos aos referidos segmentos socioculturais como o Prêmio Culturas Populares, instituído em 2007, com o objetivo de "reconhecer a atuação exemplar de Mestres e de Grupos/Comunidades praticantes de expressões das culturas populares brasileiras" ${ }^{3}$.

A partir de 2011, o MinC inicia um movimento de reestruturação, no qual, entre outras mudanças, extingue a Secretaria da Identidade e da Diversidade Cultural (SID) e a Secretaria da Cidadania Cultural (SCC); em substituição, funde as duas secretarias sob o título de Secretaria de Cidadania e Diversidade Cultural (SCD). As atribuições da SCD passam a ser implementadas por intermédio dos programas Cultura Viva e Brasil Plural, cujo objetivo é "fortalecer o protagonismo cultural da sociedade brasileira, valorizando as iniciativas culturais de grupos e comunidades excluídos e ampliando o acesso aos bens culturais, principalmente no apoio [...] [aos] Pontos de Cultura"4.

\section{O Registro de manifestações e ex- pressões culturais tradicionais e po- pulares como patrimônio de natureza imaterial (PNPI/MinC)}

Com a ampliação da noção de patrimônio e a compreensão das manifestações populares mais voltadas para a nova ótica patrimonial, consideradas como patrimônio cultural intangível ou imaterial, o MinC, por meio do CNFCP e do Departamento de Patrimônio Imaterial (DPI/Iphan), passa a contemplar as culturas populares nas políticas patrimoniais 
do Iphan com ações de preservação da memória coletiva e salvaguarda de grupos e expressões.

Ainda antes do governo Lula, em 2000, foi criado o Programa Nacional do Patrimônio Imaterial (PNPI) e instituído o Registro de Bens Culturais de Natureza Imaterial. É interessante destacar que o PNPI é resultado de uma discussão impulsionada desde os anos noventa pelos segmentos ligados à defesa do folclore e culturas populares e converge com os indicativos tirados na Convenção para a Salvaguarda do Patrimônio Imaterial, realizado pela UNESCO, em 2003.

O programa reúne uma série de ações para identificação, reconhecimento, salvaguarda e promoção dos bens do patrimônio cultural de natureza imaterial ${ }^{5}$. Conforme explica Elder Alves (2011), o PNPI opera em duas sistemáticas distintas e complementares. Primeiro, o processo de registro, que tem como etapa inicial a realização de um inventário, que reúne o maior número de informações possíveis sobre o bem em questão a ser titulado como patrimônio. E segundo, o próprio registro, que é a etapa final do inventário, isto é, a concessão do título de Patrimônio Cultural do Brasil. O processo de solicitação e registro do título de patrimônio é feito a partir da demanda de grupos e organizações político-culturais, de artistas e intelectuais, que acionam os órgãos institucionais responsáveis pelo registro. É a partir do pedido desses grupos que se inicia o processo de conversão de um bem ou manifestação, que as comunidades e grupos reconhecem como parte de seu patrimônio cultural, em patrimônio reconhecido e institucionalizado pelo Estado.

O reconhecimento do Estado de que o bem é merecedor do título de patrimônio é permeado por uma complexa relação de disputas. De acordo com Alves, há uma série de fatores em um jogo de disputas, que inclui recursos simbólicos e políticos e o acionamento de valores, como "tradição" e "autenticidade", para atestar a "riqueza incomensurável do bem". Portanto, o registro como patrimônio é alvo de interesses por parte de grupos, instituições, cidades e regiões, assim como potencializa outros processos como "as práticas de consumo simbólico-culturais e as atividades de entretenimento-turismo" (ALVES, 2011, p. 162).

Assim como Alves, Mesentier afirma que a seleção do que vem a ser identificado como patrimônio não é só produto, mas também modifica valores, convicções e relações político-culturais. Para o autor, "na medida em que um bem ou manifestação é convertido em patrimônio pelo Estado, esse bem ou manifestação cultural é ressignificado e reidentificado culturalmente, bem como reinserido na vida social em nova condição". Desta forma, essa seleção "refaz as estruturas da identidade e redefine as condições de hegemonia políticocultural" (MESENTIER, 2012, p. 210).

É possível perceber que o MinC vem adotando uma noção de maior abrangência da cultura popular. Nesse sentido, há uma clara certa equivalência conceitual do entendimento da cultura popular com a noção de patrimônio imaterial. Na lista dos bens registrados, por exemplo, tudo que foi registrado como patrimônio imaterial está circunscrito no campo das culturas populares. Com isso, podemos inferir que o PNPI visa o reconhecimento dos "bens culturais" que historicamente foram desvalorizados em relação às culturas dominantes e agora passam a ser considerados dignos de autenticação pelo Estado e pela sociedade, o que demonstra o viés de reparação e inclusão do programa.

Existem dois deslocamentos discursivos e simbólicos nesse cenário. $O$ primeiro diz respeito à revitalização do 
conceito de patrimônio, que desloca seu foco do patrimônio material de "cal e pedra", para o patrimônio imaterial, e passa a considerar que o mais importante são as pessoas e as identidades, representadas notadamente pelas populações indígenas, afrodescendentes, minorias étnicas e grupos de cultura popular. Deste modo, o conceito de patrimônio imaterial parece direcionar-se e limitar-se ao universo da cultura tradicional e popular. Outro deslocamento cerca a noção de cultura popular que passou por transformações, atualizações e ampliações que a tornaram uma questão importante nas políticas culturais a ponto de ser privilegiada tanto nas políticas da diversidade cultural, como nas políticas patrimoniais.

\section{Programa Cultura Viva}

Em 2005, o MinC cria aquela que se torna a experiência mais importante na área da cultura durante o Governo Lula, o Programa Cultura Viva (PCV) e sua ação prioritária, o Ponto de Cultura. Como define Célio Turino (2009), idealizador do programa, o Cultura Viva foi concebido com o objetivo de "descobrir o Brasil" ou "desesconder o Brasil profundo". No discurso de Turino, essas metáforas significam que era preciso entender, conhecer mais e melhor o Brasil "escondido" e "silenciado", ou seja, aquele formado pelos grupos que foram historicamente marginalizados e excluídos por uma cultura hegemônica, elitista e conservadora.

O Cultura Viva foi descrito pelo ministro Gilberto Gil como "uma política pública de mobilização e encantamento social". Sobre os Pontos de Cultura, o ministro os qualifica como "intervenções agudas nas profundezas do Brasil urbano e rural, para despertar, estimular e projetar o que há de singular e mais positivo nas comunidades, nas periferias, nos quilombos, nas aldeias: a cultura local" (GIL, 2004, p. 8).
De acordo com o discurso da Secretaria de Projetos e Programas Culturais (SPPC) ${ }^{6}$, o Cultura Viva "tem por objetivo incentivar, preservar e promover a diversidade cultural brasileira ao contemplar iniciativas culturais locais e populares que envolvam comunidades em atividades de arte, cultura, educação, cidadania e economia solidária" (IPEA, 2010 , p. 39). Os princípios do programa se relacionam ainda com a valorização de iniciativas culturais de grupos e comunidades excluídas e ampliação do acesso a bens culturais e, sobretudo, aos meios de produção cultural.

Para isso, o PCV se estruturou, inicialmente, por meio de cinco ações: Agente Cultura Viva, em parceria com o Programa Primeiro Emprego; Cultura Digital, que promove o uso de estúdio multimídia, software livre e tecnologias digitais para dar visibilidade e circulação à produção dos pontos; Escola Viva, que visa integrar os Pontos à escola; Griôs, que valoriza os mestres dos saberes populares; e Pontos de Cultura, ação prioritária e mediadora das demais ações do Cultura Viva. Além dos Pontos de Cultura, fazem parte da estruturação da ação os Pontões - Pontos especiais responsáveis pela articulação entre diversos Pontos de uma dada região - e as Redes - a mediação feita pelo poder público municipal ou estadual entre os Pontos e a esfera federal. Com o passar dos anos, o Programa foi evoluindo e concebendo outras ações e prêmios atrelados às necessidades e desenvolvimento dos Pontos de Cultura, como iniciativas que envolvem atividades de arte, cultura, educação, cidadania e economia solidária, bem como as ações Pontinhos de Cultura e Economia Viva (MinC, 2004).

O Programa Cultura Viva opera, desta forma, com a inclusão social e cultural, seguindo a ordem redistributiva e inclusiva dos programas criados no 
Governo Lula - Bolsa Família, ProUni, Fome Zero, entre outros. O seu objetivo é ampliar e garantir a inclusão de novos agentes no atendimento das políticas culturais, por meio do repasse de recursos e tecnologias digitais, sem restrição de segmento, expressão cultural, condição social ou posição geográfica às diversas manifestações da sociedade brasileira (DOMINGUES, 2010).

\subsection{Ação Ponto de Cultura}

A ação Ponto de Cultura se realiza por meio de um convênio, estabelecido a partir de edital público, entre o governo - federal, estadual ou municipal - e sociedade civil. Os proponentes agentes culturais das comunidades, organizações e instituições públicas, legalmente constituídas (com CNPJ) - devem submeter seu projeto ao MinC. Caso aprovado, os projetos recebem o apoio financeiro. A ideia é garantir o direito de produção e difusão, estimular a geração de renda, o desenvolvimento sociocultural e econômico de grupos culturais locais, que, posteriormente, são articulados em redes colaborativas.

Os Pontos de Cultura não possuem um modelo único. Cada ponto tem as especificidades e formas de organização de acordo com o grupo cultural, a realidade local e a infraestrutura existente ${ }^{7}$. Se em termos de gestão pública a ação Ponto de Cultura foi problemática e deixou um lastro de limitações e inadimplências, podemos afirmar que ela foi vitoriosa na dimensão conceitual. É interessante destacar que o Ponto de Cultura é uma produção discursiva, programática e política do Estado - definida como política de "encantamento social" -, mas que também conta com a atuação dos sujeitos participantes, em diferentes contextos de produção, na ressignificação discursiva e simbólica da Ação.

\subsection{Cultura Viva, Ponto de Cul- tura e Cultura Popular: Discursos, conceitos e ideologias}

Embora não seja o eixo prioritário do PCV e do Ponto de Cultura, um dos aspectos de destaque do Programa é o apoio às culturas populares. De acordo com a pesquisa Cultura Viva: as práticas de pontos de pontões, promovida pelo IPEA, este apoio se embasa na "ideia do reconhecimento e da valorização da diversidade, assim como da preservação da memória e das práticas e manifestações culturais ligadas a este universo" (IPEA, 2011, p. 37). A percepção de que as culturas populares trazem um capital simbólico de grande importância, que deve ser mantido, preservado e considerado em sua diversidade cultural, ganhou ampla dimensão na atuação do Programa.

É importante destacar ainda que, nos Pontos de Cultura, as culturas tradicionais e populares não aparecem ligadas ao antigo paradigma do tradicional versus moderno, elas "se misturam com práticas em geral consideradas 'modernas', como o audiovisual e a cultura digital" (IPEA, 2011, p. 38). Assim, Pontos de Coco, Jongo, Maracatu, Boi, por exemplo, utilizam dos recursos multimídia para registro de práticas e saberes tradicionais, o que também demonstra o caráter inovador desse tipo de iniciativa.

Os Pontos de Cultura se encaixam no contexto de um novo paradigma das políticas culturais (globais e nacionais), que valoriza a diversidade cultural, pelo reconhecimento e valorização das múltiplas manifestações culturais, e o protagonismo social, por meio da promoção de modos de autogestão das iniciativas culturais.

Outra grande questão é sua incorporação ao modelo de democracia cultural, na qual a cultura é encarada como expressão de cidadania, através da pro- 
moção do acesso aos meios de produção e fruição cultural como forma de contribuir para a superação de desigualdades. Este modelo também se alia às políticas para a diversidade, onde "ao valorizar as múltiplas práticas e demandas culturais, o Estado está permitindo a expressão da diversidade cultural" (CALABRE, 2007, p. 14).

Autonomia, protagonismo, empoderamento, gestão em rede e gestão compartilhada são conceitos e práticas implementadas pela Ação Ponto de Cultura, que foram sendo apropriadas nos discursos e significados pelos agentes participantes da Ação. De acordo com a formulação programática do Ponto de Cultura, a tríade autonomia, protagonismo e empoderamento são concebidos como práticas, "como processos de modificação das relações de poder e como exercícios de liberdade" (MinC, 2004, p. 34/35). Os conceitos estão ligados à cidadania e conquista de direitos, à emancipação de grupos e comunidades no sentido de seu desenvolvimento e melhoria de suas vidas, material - pela capacidade de gerar emprego e renda - e sociopolítica, pela capacidade de articulação e participação social.

Somados às novas categorias, foi aplicado o conceito de gestão compartilhada, gestão em rede ou ainda gestão transformadora para os Pontos de Cultura. Através desse conceito, propõe-se uma gestão da cultura compartilhada entre Estado e Sociedade - e ainda entre redes de pontos, por território, por linguagem, e outras múltiplas possibilidades (MinC, 2004 ; TURINO, 2009).

Entretanto, pesquisas realizadas pelo Ipea e estudos de alguns autores (TURINO, 2009 ; DOMINGUES, 2010 ; LACERDA et al., 2010) apontam que problemas com esse modelo de gestão, entraves burocráticos e a comunicação entre os Pontos e o Ministério, e até mesmo a pouca vontade política, foram os princi- pais impasses na implantação da Ação. Os grupos tiveram que se apropriar de rígidas regras, mecanismos de gestão e normas de um sistema legal inadequado e universalista, algo que não era familiar às organizações sociais e que não se adequava a demandas e realidades tão distintas das culturas brasileiras. Isso provocou, nos anos iniciais da Ação, uma série de dificuldades e problemas, como descontinuidade e interrupção de atividades. Em síntese, a prática mostrou que uma gestão que tenta ser democrática e popular, buscando romper hierarquias e narrativas tradicionais, se confrontou com uma estrutura estatal ainda elitista e conservadora, e, portanto, profundamente excludente.

Os conceitos da Ação foram concebidos como práticas de "modificação das relações de poder e como exercícios de liberdade" (TURINO, 2009). Contudo, novas questões e relações de poder se colocaram, como a instância de poder da posição de intermediário dos gestores dos Pontos (NUNES, 2011), o incômodo a algumas estruturas de poder diante desse processo de "empoderamento social" desencadeado pela Ação, entre outros.

Com isso, embora tenha contribuído para legitimar expressões culturais, fortalecer atividades, possibilitar inclusão e democracia cultural, a participação dos novos sujeitos pode também ficar limitada e condicionada a uma não reflexão política que a Ação deveria suscitar. Como têm mostrado as avaliações do Ipea e os estudos acadêmicos - e que também tem sido o tema prioritário dos encontros entre MinC e os Pontos -, as análises e reflexões sobre os problemas e avanços dos Pontos de Cultura parecem se limitar a questões de ordem administrativa. Talvez não haja, de forma mais contundente, uma profunda reflexão sobre a dimensão política do Ponto de Cultura e sobre a condução política da Ação. Os recursos de poder que os sujeitos se apropriam e os 
elementos conceituais da Ação parecem ficar relegados e são sobrepostos pelas questões burocráticas e administrativas.

Essas reflexões fazem parte da dimensão do político, que deve ser tomado na sua dimensão de conflito e antagonismo, como defende Mouffe (2009). Desta forma, as políticas para uma multiplicidade de grupos de interesse ou afirmação dos direitos de minorias devem ser tomadas a partir da dimensão política de relações de poder.

\section{Apontamentos finais}

Como podemos observar, há uma produção discursiva sobre o significado e alcance da noção de cultura popular no MinC durante o governo Lula e que tem como locus principal o PCV, e particularmente a Ação Ponto de Cultura. Esta produção se insere em uma articulação de significações e de um contexto determinado de disputas de sentido que envolve diversos âmbitos institucionais, além das próprias práticas dos agentes das culturas tradicionais e populares. A questão que se impõe nesse contexto é o do caráter inclusivo de tal noção, que se alia à de diversidade cultural e à de patrimônio imaterial, respaldando a política cultural federal.

Contudo, tal como afirmamos no início do artigo, o discurso como prática articulatória não tem sua efetividade garantida, pois ela é contingente e provisória, de modo que o rearranjo provocado pelo governo Dilma, ainda que do mesmo partido político, tem provocado descolamentos no sentido de "cultura popular".

Passados dez anos desde a implantação do Cultura Viva, o Programa reduziu consideravelmente seu conjunto de ações, restringindo-se ao Ponto de Cultura, e passa por um processo de redesenho nas gestões de Anna de Holanda e Marta Suplicy no Ministério da Cultura. Célio Turino, por exemplo, entende que há um retrocesso no Programa. O eixo central da sua análise diz respeito à abertura simbólica do governo Lula para experimentações de políticas públicas inovadoras, principalmente pela lógica da inclusão social e deslocamento de classes. Segundo Turino, "enquanto houve vontade política combinada com a baixa institucionalidade no Ministério da Cultura, foi possível avançar. Depois, tudo tornouse mais difícil" (TURINO, 2013, p. 1).

Sob o governo Dilma, as brechas para aquele tipo de experimentação feito com o PCV ficou ainda mais difícil diante da sobreposição da técnica e da gestão. Se no governo anterior a lógica da experimentação e na temática da diversidade cultura foi privilegiada na etapa inicial da sua gestão, no atual governo o discurso privilegiado passou a ser o da qualificação técnica e o destaque para as ações do campo da Economia Criativa.

Isso significa que o Cultura Viva e o Ponto de Cultura morreram? Apesar das incoerências, da considerável redução e desmonte na continuidade dessas ações, de maneira alguma eles morreram. O Ponto de Cultura mantém sua força, principalmente, no patamar discursivo, conceitual simbólico. Embora ainda existam muitos problemas e desafios, é inegável a avaliação positiva do Programa Cultura Viva e da Ação Ponto de Cultura na promoção de uma (re)distribuição dos recursos e investimentos na área da cultura em nível nacional, não mais restrita a determinados grupos ou linguagens artísticas consagradas e eruditas ou geograficamente concentradas em determinadas áreas do país. Além de novos processos de construção de políticas públicas de cultura, com a inclusão de novos atores sociais, que compõem a diversidade de manifestações culturais. Sobretudo, a nova dimensão e destaque que a política pública de cultura traz para os temas da diversidade cultural e, especialmente, da cultura popular. 


\section{Bibliografia}

ALVES, Elder P. Maia. Políticas culturais para as culturas populares no Brasil contemporâneo. Maceió: EDUFAL, 2011.

BARBALHO, Alexandre. Política Cultural: um debate contemporâneo. In: RUBIM, Linda (Org.). Organização e Produção da Cultura. Salvador: EDUFBA, 2005. p. 33-52.

BARBALHO, Alexandre. Políticas Culturais no Brasil: identidade e diversidade sem diferença. In: RUBIM, Albino; BARBALHO, Alexandre (Orgs.) Políticas Culturais no Brasil. Salvador: UFBA, 2007. (Coleção Cult). p. 37-60.

BARBALHO, Alexandre. Políticas Culturais no Brasil: Primórdios (1500-1930). Trabalho apresentado no V ENECULT - Encontro de Estudos Multidisciplinares em Cultura. Salvador: UFBA, 2009.

BARBALHO, Alexandre. Relações entre Estado e cultura no Brasil. ljuí: Unijuí, 1998.

BEZERRA, Jocastra. Quando o popular encontra a política cultural: a discursividade da cultura popular nos Pontos de Cultura "Fortaleza dos Maracatus", "Cortejos Culturais do Ancuri" e "Boi Ceará". Dissertação (Mestrado) - Universidade Estadual do Ceará, Fortaleza, 2014.

BOTELHO, Isaura. A política cultural e o plano das ideias. In: RUBIM, Albino; BARBALHO, Alexandre (Orgs.) Políticas Culturais no Brasil. Salvador: UFBA, 2007 (Coleção Cult). p. 109-132.

CALABRE, Lia. Políticas Culturais no Brasil: balanço e perspectivas. In: RUBIM, Albino; BARBALHO, Alexandre (Orgs.). Políticas Culturais no Brasil. Salvador: UFBA, 2007. (Coleção Cult). p. 87-107.

CORREA, Joana R. Ortigão. Um Conceito estratégico: as culturas populares no âmbito das políticas públicas de cultura no Brasil. In: FRADE, Cáscia et al. (Org.) Políticas públicas de cultura do Estado do Rio de Janeiro. Rio de Janeiro: UERJ, Decult, 2012. p. 41-57.

DOMINGUES, João. Programa Cultura Viva: políticas culturais para a emancipação das classes populares. Rio de Janeiro: Luminária academia, 2010.

GIL, Gilberto. Experimentação, memória e invenção. Discurso do Ministro Gilberto Gil na sole- nidade de transmissão do cargo, em Brasília, a 2 de janeiro de 2003. Caderno Cultura Viva. 3. ed. Brasília: MinC, 2004. p. 40-43.

GIL, Gilberto. Que acontece quando se liberta um pássaro? Pronunciamento sobre o Programa Cultura Viva. Berlim, Alemanha, 2 de setembro de 2004. Caderno Cultura Viva. 3. ed. Brasília: MinC, 2004. p.8-9.

INSTITUTO DE PESQUISA ECONÔMICA APLICADA. Cultura Viva: avaliação do programa arte educação e cidadania. Brasília: IPEA, 2010.

INSTITUTO DE PESQUISA ECONÔMICA APLICADA. Cultura Viva: as práticas de pontos e pontões. Brasília: IPEA, 2011.

LACERDA, Aline Pires de et al.. Programa Cultura Viva: uma nova política do ministério da Cultura. In: RUBIM, Albino (Org.) Politicas Culturais no Governo Lula. Salvador: UFBA, 2010. (Coleção Cult). p. 111-131.

LACLAU, Ernesto; MOUFFE, Chantal. Hegemonía y estratégia socialista. Hacia una radicalización de la democracia. Madrid: Siglo XXI, 1987.

MAGALHÃES, Célia Maria (Org.). Reflexões sobre a Análise Crítica do Discurso. Belo Horizonte: Faculdade de Letras, UFMG, 2001.

MAMBERTI, Sérgio. Brasil, mostra a tua cara. In: Anais do Seminário Nacional de Políticas Públicas para as Culturas Populares. São PauIo: Instituto Pólis; Brasília: Ministério da Cultura, 2005. p. 21-23.

MENDONÇA, Daniel de. Antagonismo como identificação política. Revista Brasileira de Ciência Política, $n^{\circ}$ 9. Brasília, setembro - dezembro de 2012. p. 205-228.

MESENTIER, Leonardo M. de. A natureza política do patrimônio cultural. In: FRADE, Cáscia et al. (Org.) Políticas públicas de cultura do Estado do Rio de Janeiro. Rio de Janeiro: UERJ, Decult, 2012. p. 201-212.

MINISTÉRIO DA CULTURA (MinC). Secretaria da Identidade e Diversidade Cultural. Plano Setorial para as Culturas Populares. MinC: SID - Brasília, 2010. Disponível em <http://www.cultura.gov.br/cnpc/wp-content/uploads/2011/07/ plano-setorial-de-culturas-populares.pdf. Acesso em: 01 out.2012. 
MINISTÉRIO DA CULTURA (MinC). Cultura Viva: o Programa Nacional de Arte, Educação, Cidadania e Economia Solidária. 3. ed. Brasília: MinC, 2004.

MOUFFE, Chatal. The Democratic Paradox. Londres: Verso, 2009.

NUNES, Ariel F. Pontos de cultura e os novos paradigmas das Políticas Públicas Culturais: reflexões Macro e Micro-Políticas. Rio de Janeiro: Fundação Casa de Rui Barbosa, 2011. Disponível em <http://www.casaruibarbosa.gov.br> Acesso em 20 out. 2013.

OLIVEIRA, Ana de; LOPES, Aline C. A abordagem do ciclo de políticas: uma leitura pela teoria do discurso. Cadernos de Educação, Faculdade de Educação - FaE, Programa de Pós Graduação em Educação - PPGE. Pelotas, RS: Universidade Federal de Pelotas - UFPel, 2011. p. 19-41.

ORTIZ, Renato. Cultura brasileira e identidade nacional. São Paulo: Brasiliense, 2006.

RUBIM, Albino. Políticas culturais no Brasil: tristes tradições, enormes desafios. In: RUBIM, Albino; BARBALHO, Alexandre (Orgs.). Políticas Culturais no Brasil. Salvador: UFBA, 2007. (Coleção Cult). p. 11-36.

SANTOS, Josciene et al. As políticas públicas para a diversidade cultural brasileira. In: RUBIM, Albino (Org.) Políticas Culturais no Governo Lula. Salvador: UFBA, 2010. (Coleção Cult). p. 265-286.

TURINO, Célio. O desmonte do programa CULTURA VIVA e dos Pontos de Cultura sob o governo Dilma. Revista Fórum, 2013. Disponível em <http:// revistaforum.com.br/brasilvivo/2013/07/07/o-desmonte-do-programa-cultura-viva-e-dos-pontosde-cultura-sob-o-governo-dilma/> Acesso em: 13 nov.2013.

TURINO, Célio. Ponto de Cultura: o Brasil de Baixo para Cima. Rio de Janeiro: Anita Garibaldi, 2009.

UNESCO. Recomendação sobre a Salvaguarda da Cultura Tradicional e Popular. Paris: UNESCO, 1989.
1 Jocastra Holanda Bezerra, Mestra em Políticas Públicas e Sociedade pela UECE. Integrante do Grupo de Pesquisa em Políticas de Cultura e de Comunicação (CULT.COM), Ceará, Brasil. Contato: jocastrahb@gmail.com

2 Alexandre Almeida Barbalho, Doutor em Comunicação e Cultura, Professor dos PPGs em Políticas Públicas da UECE e em Comunicação da UFC. Líder do Grupo de Pesquisa em Políticas de Cultura e de Comunicação (CULT.COM). Ceará, Brasil. Contato: alexandrealmeidabarbalho@gmail.com

3 Prêmio Culturas Populares 2012. Disponível em <http://www2.cultura.gov.br/culturaviva/ premio-culturaspopulares-2012-2/> Acesso em: 06 mar.2013.

4 DECRETO N 7.743, DE 31 DE MAIO DE 2012 - Aprova a Estrutura Regimental e o Quadro Demonstrativo dos Cargos em Comissão e das Funções Gratificadas do Ministério da Cultura. Disponível em <http://www.cultura.gov.br/scdc> Acesso em: 29 out.2013.

5 Programa Nacional do Patrimônio Imaterial. Disponível em <http://portal.iphan.gov.br/portal/ baixaFcdAnexo. do? id=201> Acesso em: 10 abr.2013.

6 A SPPC posteriormente se tornou a Secretaria de Cidadania Cultural (SCC) e atualmente integra a Secretaria de Cidadania e Diversidade Cultural (SCD).

7 Para uma análise de Pontos de Cultura voltados para as culturas populares em Fortaleza, Ceará, ver a dissertação de Jocastra Bezerra (2014), cuja pesquisa é a base das considerações desenvolvidas nesse artigo. 